\title{
THE ADVANTAGES OF A HYBRID PISTON PROP AIRCRAFT
}

\author{
Roberta FUSARO \\ Mechanical and Aerospace Engineering Department, Politecnico of Turin, Address: Corso Duca degli \\ Abruzzi 24, 100129-Turin, Italy \\ E-mail: roberta.fusaro@polito.it;
}

Received 24 September 2014; accepted 17 February 2016

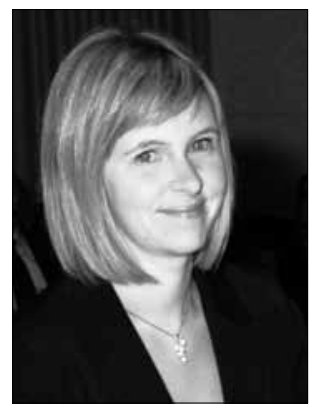

\begin{abstract}
Roberta FUSARO was born in 1989 in Turin and enrolled at Politecnico di Torino in 2008. She completed her Engineering studies in 2013 when she received her MSc Degree. In October 2013, she started her collaboration with the Aerospace Systems Engineering Research Group, in the Mechanical and Aerospace Department of Politecnico di Torino, and since January 2014 she has attended a PhD course in Aerospace Engineering. She contributed, as co-author, to some scientific articles and congress proceedings and her research is focused on Aircraft Conceptual Design, with a focus on UAVs, Hypersonic Transportation Systems, Hybrid Propulsion and Simulation Methodologies.
\end{abstract}

\begin{abstract}
The aim of this work is to present the design of a more environmental friendly aircraft that complies with existent and future emission regulations. Recent Market Outlooks were examined and a single engine piston prop was selected as a case study. Matching Charts were used to estimate the hybridization degree, meaning the ratio between the power provided by the electric motors and the total amount of power. This method allowed the over-boost advantage to be highlighted and pointed out secondary benefits of a hybrid Piston Prop. Furthermore, the zero-emission taxi possibility was evaluated. Both fuel savings forecast and safety analysis were performed, showing secondary advantages of a high hybridization degree for a single engine Piston Prop configuration. Furthermore, the additional weight related to electric motors and storage system is taken into account and state-of-the-art and innovative under-development technologies are considered. Thus, the conceptual design phase will produce many possible architectures; therefore, the last part of the work consists of a trade study necessary to select the optimal solution to design an innovative hybrid Piston Prop aircraft.
\end{abstract}

Keywords: hybrid propulsion system, preliminary system sizing, green taxi, safety, piston prop aircraft, storage system sizing.

\section{Introduction}

According to the most recent market outlooks and research studies, within Europe only the number of commercial flights will rise up to 25 million in 2050 with a noticeable increase if compared to the 9.4 million in 2011. Indeed, despite of the advent of high-speed rails, air transport will remain the principle way of conventionally satisfying the growing demand for diffused and flexible point-to-point connections. Today and tomorrow engineers should be faced with the challenge of developing innovative aircraft in order to comply with the increasing market demand, taking into account the regulations concerning environmental protection. In order to allow next generations to live in a wholesome and greener Earth with the aim of enhancing the air quality in the very proximity of airports and diminishing the aviation footprint, regulators of the most important Countries have signed different proposals. In particular, the European Union and other 193 Countries signed a very important agreement during the United Nations Convention on Climate Change (1992), preceding the well-known Kyoto Protocol (1997). Despite the inevitable contrasts between the European Union Trading Scheme (Leggett et al. 2012) and the EU ETS Prohibition Act of 2011 (Public Law 2012) approved by the United States Senate, there are common and great economic interests in developing new environmentally friendly aircraft. In this context, a collective effort interests the public and private projects performed not only by the major companies but also by small and medium enterprises, academia and research laboratories all over the world. 
In such an environment, the idea of developing a conceptual design of a piston prop aircraft powered by a hybrid propulsive system has been raised. In particular, this article begins with a brief description of the role of Piston Prop aircraft in today's fleet (Section 1). Some market outlook results are also provided in order to clarify and explain the decision of selecting a small piston prop aircraft as a reference model.

Section 2 enters in the detail of the hybrid propulsive system applications in the transport sector, with a particular focus on the aeronautical field. Then, two typical system architectures are defined and from them, accounting for the best solution in terms of possible obtainable advantages, the parallel hybrid solution has been selected for the purposes of this paper.

Section 3 is the core of this article. It proposes the preliminary sizing of a small hybrid piston prop aircraft. After a preliminary overview of the methodology that has been followed during the design process, each step is examined in detail. The very first step to be performed is the hybridization degree selection, which is a direct consequence of the power requirements detected at the beginning of the project. Then, once the main goal to be pursued is clear, the electric motor, the thermal engine and the storage system can be sized. Furthermore, this article proposes a basic useful algorithm to take into account the weight related to the additional mechanical elements that should be included in a hybrid configuration. Moreover, this article suggests performing a fuel estimation in order to verify the benefit in terms of weight and pollutant emissions.

Once the methodology has been shown, a trade off analysis is reported in Section 4. Accounting for the different requirements that the designer wants to optimize, it is necessary to evaluate the feasibility of the design and to select optimal solutions. Obviously, the main goal will be to maximize performances and minimise the additional weight.

\section{The role of Piston Prop aircraft in todays fleet}

Since the beginning, transportation has been one of the main engineering fields that is in a continuous growth. This increasing trend also involves aeronautics, in which the future expectations reveal an exponential growth in flight demand. This phenomenon has been forecasted by different market outlooks and scientific publications (GAMA 2010) and many studies have been carried out in order to focus on the possible environmental drawbacks. As it is shown in Fig.1, the positive trend in the number of possible passengers and flights will cause a terrible increase in the total amount of pollutant emissions. In order to comply with recent and future emission regulations that impose a maximum acceptable threshold for the pollutant in the atmosphere, engineers

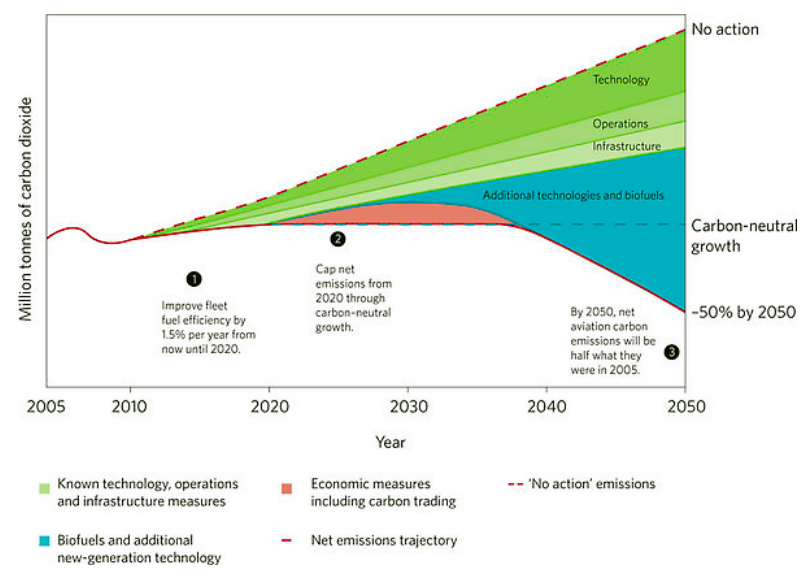

Fig. 1. Pollutant emission trends for the period 2005-2050

should develop and propose innovative propulsive solutions. Furthermore, new technologies should be proposed in order to enhance airport operations and innovative fuels should be adopted by a higher number of companies. As it is well highlighted in the picture, the first established goal is to reach a carbon neutral growth by 2020; however, the most demanding aim is to reach a $50 \%$ reduction in pollutant emissions compared to the 2005 emission levels. In this context, the hybrid propulsion system could find the right soil to be developed.

\subsection{Recent market outlook}

Among the different classes of aircraft, it is useful to select the one with the highest possible impact in order to reach remarkable results. For this reason, in the following two sections the results of a recent market outlook and the selection of a reference aircraft are proposed. As far as civil aircraft are concerned, it is possible to subdivide them into two main categories: transport aircraft and general aviation aircraft. The former is composed of all flight machines devoted to transport under payment. This category includes aircraft devoted to transportation of both people and goods. Aditionally, the general aviation category can be defined using the definition proposed by the International Council Of Aircraft Owner And Pilot Associations: General Aviation and aerial work operations are all those not considered to be operated by airlines, charter operators or the military. In order to comply with the aim of this paper, the second category has been studied in-depth. The greatest attention was paid to the North American market because of the availability of the data and the high number of aircraft sold in these Countries which makes this data representative of the whole fleet. The pie-chart in Fig. 2, illustrates the different composition of the North American General Aviation fleet with respect to the propulsive system. It is evident that piston engine airplanes have a dominant role, representing $\backslash 40 \%$ of the entire fleet considered. It is also useful to remember that, in addition to the role played within the general aviation fleet, ultra-light 
aircraft should also be considered, because almost all aircraft of this type have a piston engine. Piston engine airplanes also have other peculiarities that make them interesting for further in-depth studies. In particular, they have a leading position in the number of flown hours and in the years of service. The first of these characteristics means that this aircraft type has a high impact on the environment as far as the pollutant emissions are concerned. On the other hand, the high values of service life highlight a high number of possibly retired machines in the next few years (see Figs 3 and 4). Eventually, the Aircraft Market Outlook shows that it can be convenient to design and develop an innovative piston engine aircraft able to comply with future emission regulations; therefore, the research group which I belong to decided to study a hybrid version of a piston engine aircraft.

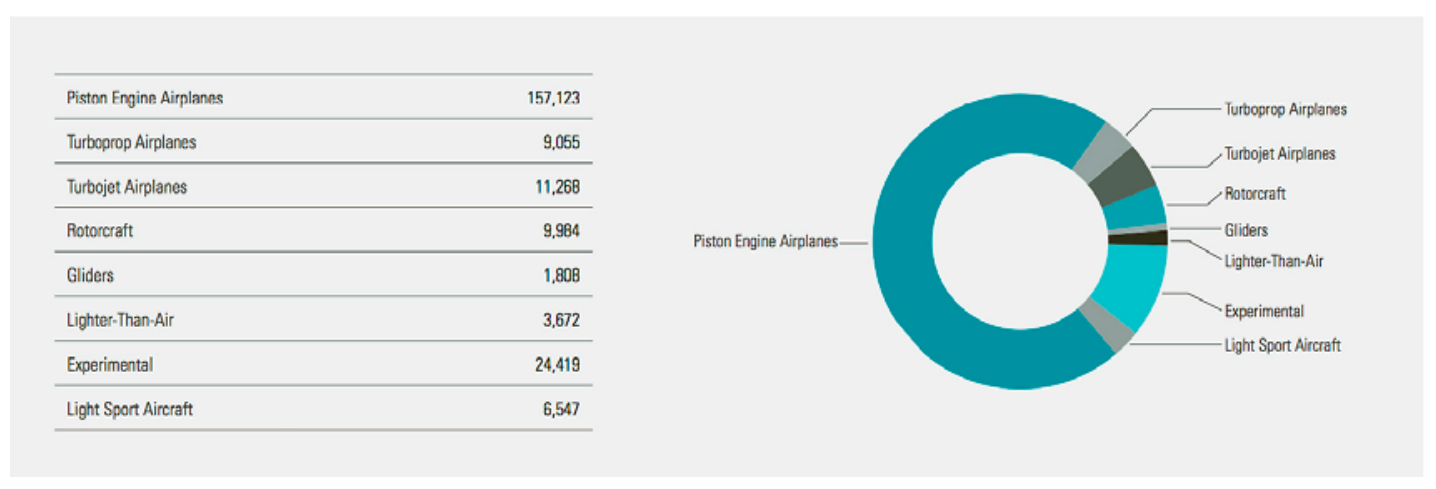

Fig. 2. Number of piston engine airplanes in North American market. From (GAMA 2010)

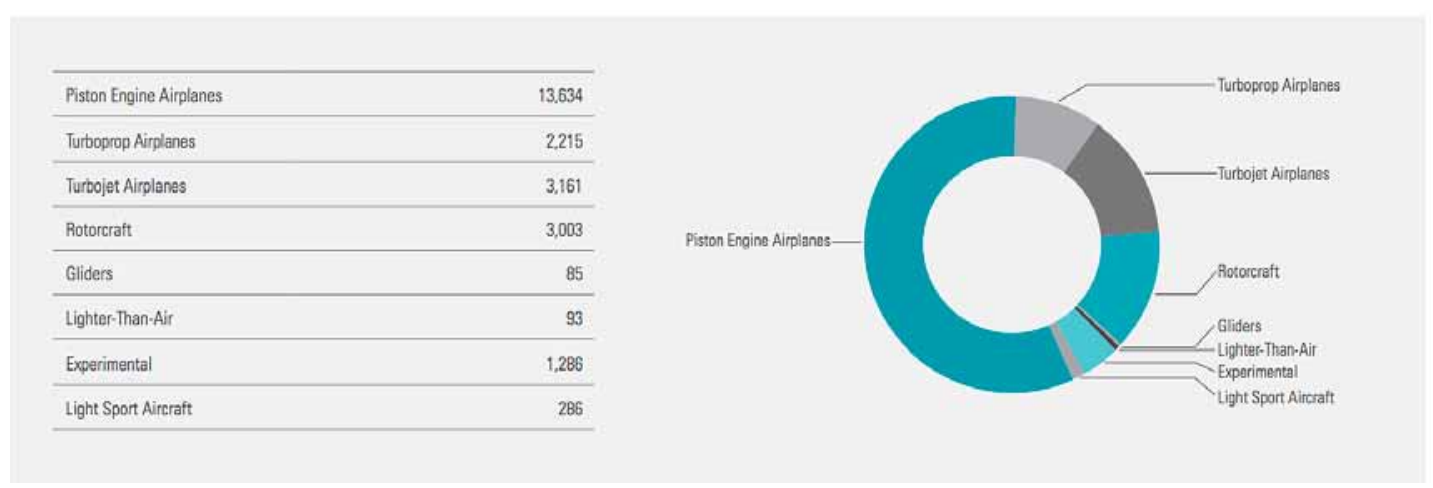

Fig. 3. Total amount of flight hours of piston engine airplanes in North American market. From (GAMA 2010)

\begin{tabular}{|c|c|c|c|c|c|c|c|}
\hline Aireratt Type: & Engine Type & Seats & $\begin{array}{l}\text { Average Age in } 2005 \\
\text { in Years }\end{array}$ & $\begin{array}{l}\text { Average Age in } 2006 \\
\text { in Years }\end{array}$ & $\begin{array}{l}\text { Average Age in zont } \\
\text { in Years }\end{array}$ & $\begin{array}{l}\text { Avergge Age in zolos } \\
\text { in Years }\end{array}$ & $\begin{array}{l}\text { Average Aga in } 2003 \\
\text { in Years }\end{array}$ \\
\hline \multirow[t]{7}{*}{ Single-Engine } & \multirow[t]{5}{*}{ Piston } & $1-3$ & 37 & 38 & 38 & 48 & $\cdot$ \\
\hline & & 4 & 35 & 36 & 36 & 38 & - \\
\hline & & $5-7$ & 30 & 31 & 32 & 34 & - \\
\hline & & $8+$ & 44 & 44 & 43 & 49 & $\cdot$ \\
\hline & & All & $*$ & $\cdot$ & • & • & 42 \\
\hline & Turboprop & All & 13 & 10 & 14 & 14 & 16 \\
\hline & Jet & All & 34 & 34 & 35 & 44 & 44 \\
\hline \multirow[t]{7}{*}{ Multi-Engine } & \multirow[t]{5}{*}{ Piston } & $1-3$ & 32 & 32 & 33 & 49 & • \\
\hline & & 4 & 35 & 35 & 35 & 36 & • \\
\hline & & $5-7$ & 36 & 36 & 39 & 39 & - \\
\hline & & $8+$ & 38 & 39 & 40 & 42 & . \\
\hline & & All & $\cdot$ & $\cdot$ & $\cdot$ & $\cdot$ & 41 \\
\hline & Turbeprop & All & 25 & 26 & 27 & 29 & 28 \\
\hline & Jet & All & 16 & 16 & 16 & 16 & 17 \\
\hline All Airplanes & & & 34 & 35 & 35 & 39 & 39 \\
\hline
\end{tabular}

Fig. 4. Average service year of North American fleets. From (GAMA 2010) 


\subsection{Reference aircraft}

In order to perform trade off studies and parametric analyses, it is useful to define a reference aircraft. It would be meaningful to make a comparison between the performances of existing aircraft and those that could be achieved by new hybrid aircraft. In particular, as it has been mentioned above, a small single engine Piston Prop has been chosen: this type of airplane is the most numerous considering the global fleet. Furthermore, evaluating their service lives, many of them would be retired in the next few years. These facts suggest that small Piston Prop engine planes are eligible to be transformed into hybrid aircraft. Fig.5 shows a 3-view of the selected aircraft and summarizes the main technical data.

\begin{tabular}{|l|ll|}
\hline & Passengers & 2 \\
Wing area & $10 \mathrm{~m}^{2}$ \\
MTOM & $1200 \mathrm{~kg}$ \\
& Power [hp] & $260 \mathrm{hp}$ \\
& Power [kW] & $195 \mathrm{~kW}$ \\
& Take-off run & $275 \mathrm{~m}$ \\
& Landing roll & $400 \mathrm{~m}$ \\
\hline
\end{tabular}

Fig. 5. Reference aircraft: 3-view sketch and technical data

\section{Hybrid propulsion system review}

The idea of developing innovative propulsive solutions for aeronautics has different pushing motivation depending on the final utilization of this technology. As far as the military field of application is concerned, hybrid propulsive solutions appear tempting from the performance point of view. The hybrid technology can allow the engineers to design architectures with a lower acoustic emission level and also a lower thermal trace. Moreover, the presence of an additional electric motor, if appropriately sized, could be exploited to enhance the manoeuvrability of the airplane, accounting for an additional amount of available thrust. In contrast, in the civil field hybrid propulsion technology is one of the mainstreams to reduce pollutant emissions; in order to reach this goal, there are many research projects under-development, both in academic and industrial environments.

\subsection{Overview of hybrid technologies in transportation}

Before starting with the description of possible aeronautical hybrid architectures, it is convenient to take a look at all those transport sectors in which this technology has been developed in the past decades. This research activity is very useful for exploiting know how and past experience.

As far as the transport sector is concerned, the naval field has been one of the first sectors to exploit electric motors in order to produce power to perform different activities. In particular, hybrid technologies have been developed for the submarines that could not use the thermal engine under the sea level, due to the lack of air and impossibility of draining the combustion's product. In the naval field, further inventions have been proposed. Among the most successful ones, the Azimuth thrusters (Adnanes 2003) and the Podded Propulsion (McCoy 2002)can be mentioned.

Undoubtedly, automotive engineering plays a fundamental role in proposing and developing solutions that have a great impact on the market, attracting an ever-higher number of customers. In this field the term hybridization degree has been proposed. Avoiding detailed and specialized equations, the hybridization degree can be defined as the ratio between the power produced by electric motors and the total amount of power available for propulsive objectives. In this very competitive environment, many constructors have developed different solutions reaching different levels of hybridization. In the past (Husain 2010) has proposed to distinguish all hybrid cars into three families: Micro Hybrid, Mild Hybrid and Full Hybrid depending on the different hybridization degree. The first group is composed of those vehicles in which there is an electric motor devoted to producing the right amount of power support secondary activities, such as the Start\&Stop. In order to recover the level of energy in the storage system a Regenerative Raking System can be implemented on board. As far as the Micro Hybrids are concerned, the power produced by the electric motor can be exploited to produce thrust, supplying an additional amount of power during the most demanding phases, like starting and overtaking. The last category include those vehicles that are able to exploit power coming from an electric source to perform short and medium travel, avoiding the use of thermal engines. Nowadays, accounting for the stateof-art technologies, Micro and Mild Hybrid Automotive applications could be exploited in aeronautics while the Full hybrid technologies require storage systems with a higher power-to-weight ratio to be achievable.

\subsection{Hybrid propulsion systems in aeronautics}

Considering the hybrid propulsion systems applied to the aeronautic field, it is possible to identify two main architectures: serial and parallel hybrid solutions. The following two sections are focused on describing the main functionalities of these architectures and the possibility of exploiting these hybrid functionalities in all different phases of the project.

\subsubsection{Serial and parallel hybrid architectures}

As far as the serial hybrid is concerned, as seen in Figure $6 \mathrm{a}$, the electric motor is the main element of the system. It is directly connected to the propeller and it can be supplied by the thermal engine with a proper generator or by a storage system. The very first aircraft equipped 
with a similar propulsive system was the DA36 E-Star (Siemens 2011), exhibited in le Bourget on June 2011. It has an electric motor of about $70 \mathrm{~kW}$ and a thermal engine able to supply the propeller with an additional power of $30 \mathrm{~kW}$. Despite the possibility of executing a lower emission cruise and ensuring an additional power during take off and climb guaranteeing a wider safety margin, the configuration was rejected for the benefits of parallel hybrid architecture. As highlighted in Figure 6b, the gearbox is the key element of this system: it permits to add the power produced by thermal engine to the electric power provided by storage system. An example of this technology in aeronautics is the aircraft produced by Flight Design, whose propulsion system is composed of a thermal engine of about $85 \mathrm{~kW}$ and a Permanent Magnet electric motor able to produce the maximum power of about $30 \mathrm{~kW}$.

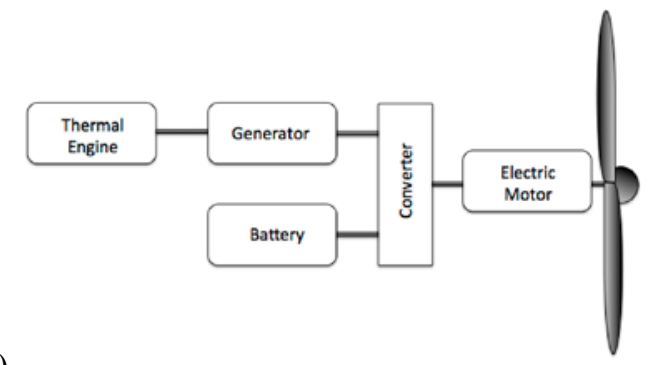

a)

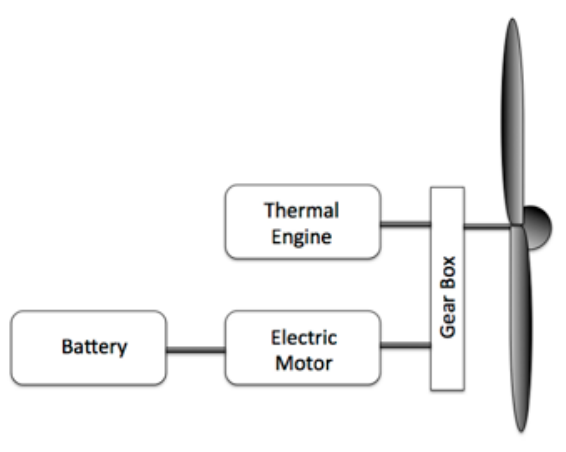

b)

Fig. 6. Serial (6 a) and parallel (6 b) hybrid architectures
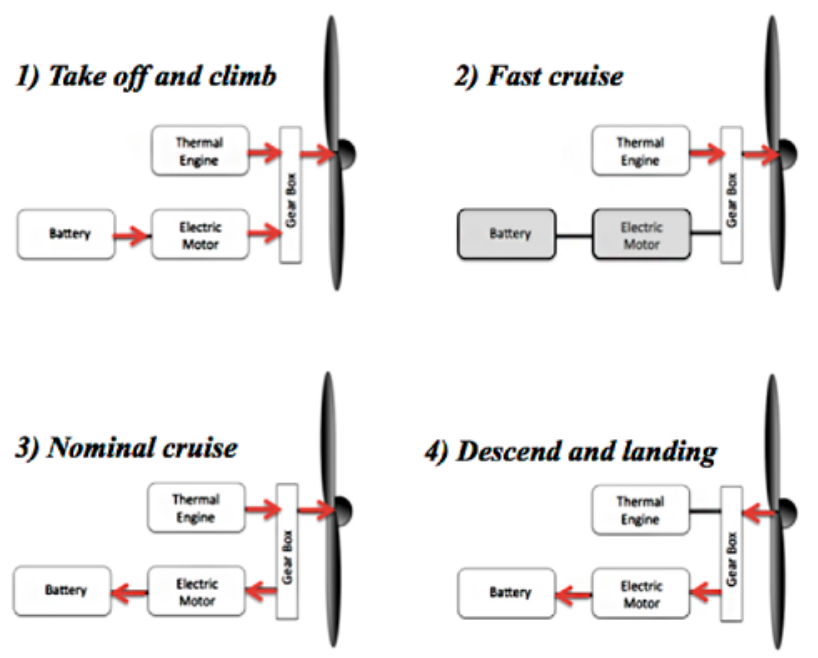

Fig. 7. Parallel hybrid exploitation in different phases
Intermediate configurations of the two mentioned here already exist, especially in the automotive area. In contrast, they seem to be characterized by a higher level of weight and complexity, implying an additional risk of failure. Considering that the parallel hybrid solution should be the configuration with the minimum additional weight, this technology was selected to start the conceptual design of a hybrid aircraft. Figure 7 shows the different operative modes of a parallel hybrid system. Before starting with the description of the utilization of this propulsive system in different project phases, it is convenient to remark that the proposed hybrid configuration should have the same total amount of power compared to the selected reference aircraft. Firstly, in this way, all the comparisons make sense. Moreover, the redistribution of power between the electric motor and the thermal engine makes re-scaling possible. With these basic assumptions, it is clear that during the most power demanding phases there is the need of supplying the aircraft propeller using both the thermal engine and the electric motor. This is the typical situation that happens during the take-off phase and the first climb segment as it is revealed in the scheme. As far as cruise is concerned, it is useful to deal with the fast cruise phase and the nominal one separately. In the first case, the power produced by the thermal engine is used to produce thrust. Conversely, during cruise with lower speed requirements, only part of the power produced by the thermal engine is devoted to propulsion. The residual thermal power is used to recover the energy from the storage system. This recharge process is completed during the descent and landing phase, when the propeller with a proper pitch angle can supply the electric motor, which acting as a generator can recharge the connected storage system. This is a very important phase because, as it will be detailed later on, the storage system could be used to supply the aircraft on the ground, in order to perform taxi operations thus avoiding pollutant emissions. In the following sections, I will refer to this phenomenon with the term Green Taxi.

\section{Hybrid Piston Prof aircraft sizing}

This section describes the preliminary sizing methology used in order to design an innovative aircraft with a hybrid propulsion system. It follows the genearal steps proposed by many publications (Chiesa et al. 2012), focused on System Engineering but is reported here because of some specific aspects.

\subsection{Overview of methodology}

The design of an aircraft has always been seen as a great adventure and a dream for many engineers, but in order to design a useful and successful machine, it is better to follow a precise basic activities flow. Many publications and books propose codified processes, already 


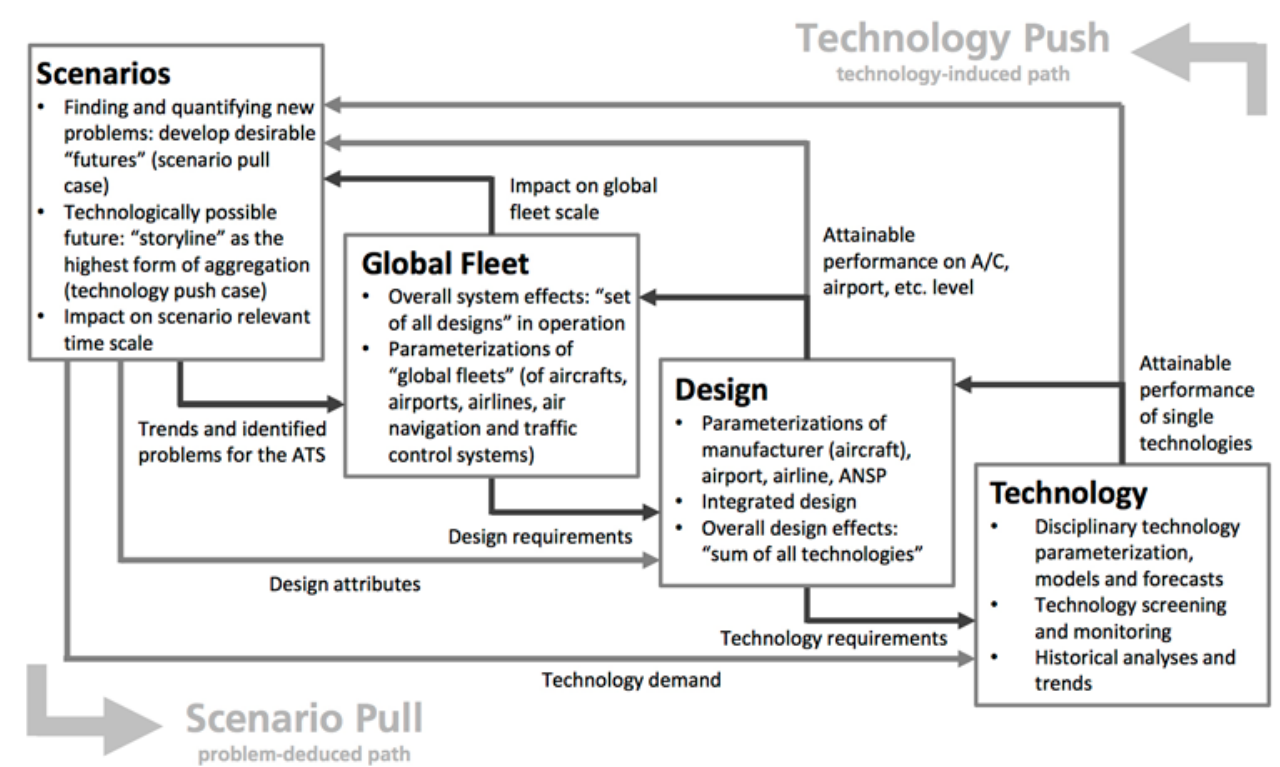

Fig. 8. Project development strategies. From (Gosh 2014)

implemented within the major aerospace companies. On the other hand, it is important to notice that the design of an aircraft powered by a hybrid propulsion system should take into account this aspect from the beginning of the conceptual design phase. Indeed, the choice of this specific propulsion system could imply different constraints regarding aircraft structure, mechanics and propulsion. For the above-mentioned reasons, the author understands the need of proposing an innovative solution for taking into account the presence of a hybrid propulsive architecture from the beginning of the project.

The very first step, in accordance with (NASA 2014) and (INCOSE 2014) once the main objectives have been defined, is the determination of first level requirements and constraint definition. In particular, in case of the preliminary design of a hybrid propulsion system, they are a direct consequence of the goals the project should accomplish. Moreover, as it will be seen in the following subsection, in addition to the traditional weight and balance constraints, in this very early design phase, the basic power requirements should be used. Once they have been derived, they should lead the first sizing attempt of the two power sources: the thermal engine and the electrical motor. Then, using different techniques, the general characteristics in terms of weight, power and volume can be evaluated for the main components of the propulsion system. This is a typical example of a bottom-up project that, starting from an innovative technology, wants to design the whole system (e.g. the aircraft) by exploiting it. Figure 8, taken from (Gosh 2014) highlights the two possible ways of designing an innovative aircraft. The design process is not a direct flow representable with a straight line. It is more similar to a series of concatenated optimization circles that shows iterative and recursive characteristics.

\subsection{Power requirement identification and hybridization degree selection}

As it has been anticipated in the previous section, the starting point in a hybrid aircraft design process is the definition of the hybridization degree. This is an automotive derived concept that means the percentage coming from the ratio between the power originated by the electric motor and the total amount of propulsive power. This value should be selected in order to ensure the aircraft's compliance with several top-level power requirements. To perform this task, I would suggest to use the Matching Chart Method. For the purposes of this article, I want to propose the use of the enhanced version of the one suggested in (Fioriti 2014). This tool, called he ACAD, Adaptable Conceptual Aircraft Design, was developed by ASSET, AeroSpace System Engineering Team, a Research Group at Politecnico di Torino. Taking into account a restricted number of mandatory inputs, the ACAD tool is able to evaluate general aerodynamic characteristics and to perform the preliminary weight estimation and sizing of the aircraft. As it is clearly shown in Fig. 9, it is a graphical output that relates the power requirements for all mission phases to the different values of wing loading.

In detail, the different power requirements that would lead the design are revealed when considering the propulsive need of each single mission phase. In particular, accounting for a typical mission of an aircraft like the one defined as the reference model, the following phases can be considered:

- taxi out (taxiing performed by the aircraft leaving the airport);

- take off and climb;

- cruise; 


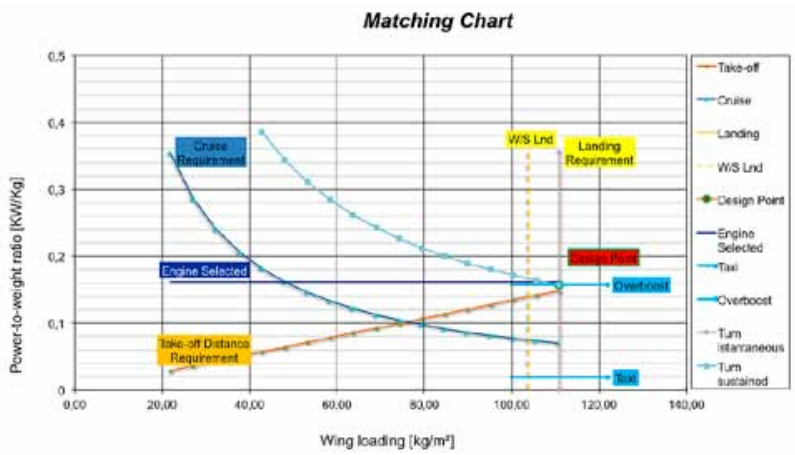

Fig. 9. Matching Chart for the reference aircraft

- sustained turn;

- descent and Landing;

- taxi in (taxiing performed by the aircraft entering the airport).

The ACAD tool is able to evaluate the power requirements of each mission segment, at a different wing loading, for the reference aircraft that has been considered. The Matching Chart provided in Fig. 9 shows the output results of this tool applied to a reference aircraft like the one described in Fig. 5. Please note that in the case in which the reference aircraft is an existing one, the matching chart can reveal very interesting design peculiarities. In this case, for example, it should be noticeable that the thermal engine is designed in order to optimize two of these requirements (the power required to perform the take off and the sustained turn). As far as the taxi phases are concerned, the power required has been evaluated using the basic geometrical data of the propeller, the maximum take off weight and the runway-wheel friction coefficient, in order to estimate the maximum drag force that the aircraft should overcome. This taxi requirement evaluation is an innovation introduced within the ACAD tool and for this reason it described further. The first step is the definition of the speed ratio, as reported in Eq.(1):

$$
\gamma=\frac{V}{\Omega R}
$$

where $V$ indicates aircraft speed, $\Omega$ - angular speed of the propeller, $R$ - radius of the propeller.

This value enables to use the three graphics reported in Fig. 10 and to obtain the Thrust $(\tau)$ and Torque $(\chi)$ coefficients and to estimate the efficiency of the propeller once the pitch angle $(\beta)$ has been selected Then, using the following equations, Thrust $T$ and torque $C$ can be estimated:

$$
T=\tau \cdot \rho \cdot \Omega^{2} \cdot R^{4},
$$

where: T - thrust; $\rho$ - air density; $\tau$ - thrust coefficient; $\Omega$ - propeller rotational speed; $\mathrm{R}$ - propeller radius:

$$
C=\chi \cdot \rho \cdot \Omega^{2} \cdot R^{5},
$$

where: $\mathrm{C}$ - torque; $\chi$ - torque coefficient; $\rho$ - air density; $\Omega$ - propeller rotational speed; $\mathrm{R}$ - propeller radius.
The power required is calculated by:

$$
P_{\text {prop }}=C \cdot \Omega \text {, }
$$

where: $P_{\text {prop }}$ - power required; $\mathrm{C}$ - torque; $\Omega$ - propeller rotational speed.

To evaluate the actual possibility of performing an electric taxi, the amount of power necessary to counteract wheel to ground friction forces shall be estimated:

$$
F_{\text {friction }}=\mu m g \text {, }
$$

where $F_{\text {friction }}-$ friction force acting on wheels; $\mu$ - friction coefficient; $m$ - maximum take off mass; $g$-Earth gravitational acceleration.

In this case, the following inequality (Eq. 6) is verified and the aircraft with the hypothesized propeller would be able to perform the taxi:

$$
F_{\text {friction }} \leq n_{\text {propellers }} \frac{T}{\eta} \text {. }
$$

$F_{\text {friction }}$ indicates friction force acting on wheels; $n_{\text {pro- }}$ pellers - number of propellers; $T$ - torque; $\eta$ - propeller efficiency.

Once all the power requirements have been derived (they are summarized in Table 1), the matching chart would suggest to the designer how to select the hybridization degree. Indeed, the traditional propulsive system, as it is well shown in Fig. 9, is optimized in order to supply the maximum power level during the most demanding phases (i.e. take off and turn). This is a little bit detrimental for the thermal engine because it works at its maximum rating (and efficiency level) only few minutes per flight. This consideration should lead the designer to size the thermal engine in order to comply with the cruise requirement and to project that the electric motor would fulfil the take off and turn requirements. Moreover, it should also be verified whether the power produced by the thermal engine is compliant with the taxi requirement. In the positive case, the aircraft should be able to perform the so-called Green Taxi, i.e. to move on ground using the electric motor only, without pollutant emissions.

Table 1. Power requirements for the reference aircraft

\begin{tabular}{ll}
\hline Mission phase & Power requirement \\
\hline Take off and initial climb & $180 \mathrm{~kW}$ \\
\hline Sustained Turn & $190 \mathrm{~kW}$ \\
\hline Cruise & $114 \mathrm{~kW}$ \\
\hline Taxi & $23 \mathrm{~kW}$ \\
\hline
\end{tabular}

All the previous considerations about the different power requirements of the several considered mission phases lead to the selection of the hybridization degree. As a first attempt, in order to guarantee the exploitation of the electric motor for over-boost purposes and the possibility of performing the green taxi, a hybridization 


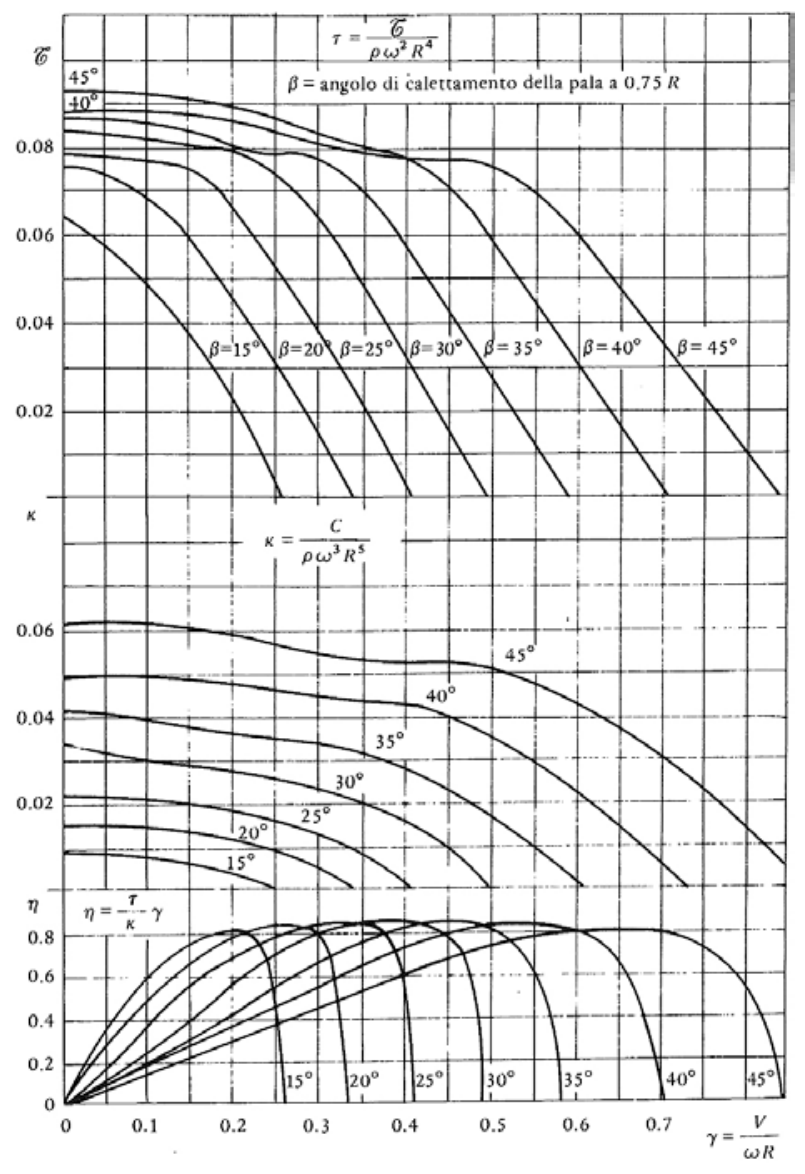

Fig. 10. Propeller diagrams. From (Lausetti 1992)

degree of $41 \%$ has been selected for the reference case selected in this paper. It means that the hybrid propulsion system should be equipped with a thermal engine able to guarantee at least $115 \mathrm{~kW}$ (compliant with the cruise requirement) and an electric motor of $80 \mathrm{~kW}$. In this way, the selected electric motor has the capability of performing green taxi and, in addition to the power produced by the thermal engine, can guarantee the necessary overboost to fulfil the take off and turn requirements

The following sections will suggest general criteria to perform a general weight estimation for this underdevelopment propulsive configuration, mainly using statistical data. In particular, the thermal engine, electric motor and storage system will be examined and results for the reference case will be provided in the following subsections.

\subsubsection{Thermal engine sizing}

Considering maintaining the same total available power of the reference aircraft, the evaluation of the hybridization degree allows the designer to select the power that the thermal engine should guarantee. Once this value is known, several sizing criteria can be applied. Besides the selection of reference engines, the author suggests to use
Eq. 7, in order to estimate the weight of each thermal engine, in a first attempt:

$$
W_{\text {thermal engine }}=P_{\text {th.eng. }} \cdot d_{\text {th.eng. }},
$$

where $\mathrm{W}_{\text {thermal engine }}$ - weight of the thermal engine; $P_{t h}$. eng. - power of the thermal engine; $d_{\text {th. eng. }}-$ thermal engine power density.

This last value can be obtained statistically. In particular, for piston engines, $1 \mathrm{~kg} / \mathrm{kW}$ is suggested. The numerical estimation for the selected case study is reported in Table 2.

Table 2. Summary of thermal engine sizing

\begin{tabular}{|c|c|c|}
\hline & Characteristics & Values \\
\hline \multirow{2}{*}{ Assumptions } & $\mathrm{P}_{\text {th.eng. }}$ & $115 \mathrm{~kW}$ \\
\hline & $\mathrm{d}_{\text {th.eng. }}$ & $1 \mathrm{~kg} / \mathrm{kW}$ \\
\hline \multirow[b]{2}{*}{ Results } & $\mathrm{W}_{\text {thermal engine }}$ & $115 \mathrm{~kg}$ \\
\hline & $\begin{array}{l}\text { Advantage with respect to the } \\
\text { traditional configuration }\end{array}$ & $-75 \mathrm{~kg}$ \\
\hline
\end{tabular}

\subsubsection{Electric motor sizing}

Similarly, statistical data can be used in order to estimate the weight of the electric motor. The following equation can be used:

$$
W_{\text {electric motor }}=P_{\text {ele.mot. }} \cdot d_{\text {ele.mot. }},
$$

where $\mathrm{W}_{\text {electic motor }}-$ weight of the electric motor; $P_{\text {ele }}$ mot. - power of the electric motor; $d_{\text {ele.mot }}$ - electric motor power density.

Please notice that this estimation is valid not only in order to evaluate the additional weight related to the new electric machines introduced into the architecture, but can also be used in order to evaluate the reduction in weight due to the elimination of the Starter and Generators (about $20 \mathrm{~kg}$ ).

Table 3. Summary of electric motor sizing

\begin{tabular}{lll}
\hline & Characteristics & Values \\
\hline \multirow{3}{*}{ Assumptions } & $\mathrm{P}_{\text {ele. mot. }}$ & $80 \mathrm{~kW}$ \\
\cline { 2 - 3 } & $\mathrm{d}_{\text {ele. mot. }}$ & $\begin{array}{l}0.65 \mathrm{~kg} / \\
\mathrm{kW}\end{array}$ \\
\hline \multirow{3}{*}{ Results } & $\mathrm{W}_{\text {electic motor }}$ & $52 \mathrm{~kg}$ \\
\cline { 2 - 3 } & Disadvantage respect to the & $+32 \mathrm{~kg}$ \\
& traditional configuration & \\
\hline
\end{tabular}

\subsection{Storage system sizing}

The storage system sizing is one of the most relevant topics in the hybrid configuration definition. This is due not only to the central role that it plays but also to the stateof-the-art technologies that put a brake to this "electrical revolution". The very first step is the evaluation of the 
amount of energy that should be stored. As it is clearly visible in Eq. 9, this value depends on the Maximum Power Rating to supply and the period of time during which the system should be fed.

$$
\left(E_{\text {stored }}\right)_{i-\text { phase }}=P_{i} \cdot t_{i} \cdot \frac{k_{s i}}{k_{c i}},
$$

where $\left(E_{\text {stored }}\right)_{i-\text { phase }}$ - energy to be stored for a defined i-phase; $P_{i}$ - power required to accomplish the i-phase, $t_{i}-$ time required to accomplish the i-phase power required to accomplish the i-phase; $k_{s i}$ - safety factor for the i-phase; $k_{c i}$ - charge and discharge efficiencyfor the i-phase.

In detail, the safety factor is a coefficient that inserts a degree of uncertainties in the evaluation, making the estimation conservative. Conversely, a discharge coefficient is required in order to overcome the problem of having a single set of cells supplying the electric motor in several different conditions. As far as the over-boost phase is concerned, the battery should guarantee a high flux of energy in a very short period of time. On the other hand, there are other conditions like the taxi during which the discharge rate required is lower. In order to properly size the storage system, the optimal working condition should be selected and then proper detrimental factors should be estimated for all the other mission phases. Moreover, in order to estimate the weight related to this subsystem, the type of batteries should be selected. Recent studies reveal that new generation storage reach higher levels of both weight and volume density. Using statistical data to make assumptions about mass ( $\left.\rho_{m}\right)$ and volume $\left(\rho_{v}\right)$ density, Eq. 10 and Eq. 11 allow to evaluate both storage system weight and volume. The multiplicative coefficient that appears in the two following equations takes into account the presence of a Battery Management System (BMS). It is the electronic control unit required by the storage system in order to control, regulate and distribute the power to the users. Besides different types of storage systems with a wide range of capability, an average additional weight of around $20 \%$ of the global storage system can be considered:

$$
W_{\text {storage sys }}=\frac{E_{\text {stored }}}{\rho_{m}} \cdot k_{B M S},
$$

where $W_{\text {storage system }}$ - storage system weight; $E_{\text {stored }}$ - energy stored in the storage system; $\rho_{m}$ - mass density; $k_{B M S}$ - Battery Management System coefficient:

$$
V_{\text {storage sys }}=\frac{E_{\text {stored }}}{\rho_{v}} \cdot k_{B M S},
$$

where $V_{\text {storage system }}$ - storage system volume; $E_{\text {stored }}$ - energy stored in the storage system; $\rho_{v}$ - volume density; $k_{B M S}$ - Battery Management System coefficient.

Notice that the higher the energy stored is, the more functions the system can exploit. Conversely, the additional weight is not negligible, and for this reason, tradeoff studies are required in order to optimize the system performances and design.

The size of the storage system is a direct consequence of the mission phases during which it has been decided to guarantee the battery supply to the electric motor. From the point of view of the performance and the pollutant emissions, the best choice would be to size the storage system in order to make it possible for the the airplane to perform all the on-ground activities using only the electric motor, and additionaly to use this electrical source during take off and eventually in case of manoeuvers. Unfortunately, using state-of-art technologies, this sizing attempt would result in a too heavy configuration (Tab. 7). Consequentely, two different strategies can be adopted, hypothesizing to exploit only taxi activities (Tab. 5) or overboost (Tab. 6).

Table 4. Inputs required for the storage system sizing

\begin{tabular}{llll}
\hline & $\begin{array}{l}\text { Electric motor power } \\
\text { requirement }\end{array}$ & Phase duration & Discharge coefficient \\
\hline Taxi out & $23 \mathrm{~kW}$ & $0.0833 \mathrm{~h}$ & 0.9 \\
\hline Take-off and initial climb & $80 \mathrm{~kW}$ & $0.0167 \mathrm{~h}$ & 0.2 \\
\hline Final climb & Thermal Engine only & & \\
\hline Cruise & Thermal Engine only & & \\
\hline Descend & Thermal Engine only & & 0.9 \\
\hline Landing & Thermal Engine only & & \\
\hline Taxi in & $23 \mathrm{~kW}$ & $0.0833 \mathrm{~h}$ & \\
\hline
\end{tabular}

Table 5. Storage system sizing to support Green Taxi

\begin{tabular}{lll}
\hline \multirow{3}{*}{ Supported Operations } & Taxi in & $\checkmark$ \\
\cline { 2 - 3 } & Take-off and initial climb & $\checkmark$ \\
\cline { 2 - 3 } Storage system results & Taxi out & $16.7 \mathrm{kWh}$ \\
\hline & $\mathrm{E}_{\text {stored }}$ & $100 \mathrm{~kg}$ \\
\hline
\end{tabular}


Table 6. Storage system sizing to support the over-boost

\begin{tabular}{lll}
\hline \multirow{2}{*}{ Supported Operations } & Taxi in & $\checkmark$ \\
\cline { 2 - 3 } & Take-off and initial climb & \\
\hline Storage system results & Taxi out & $24 \mathrm{kWh}$ \\
\hline & Wstored & $143 \mathrm{~kg}$ \\
\hline
\end{tabular}

Table 7. Storage system sizing to support Green Taxi and over-boost

\begin{tabular}{|c|c|c|}
\hline \multirow{3}{*}{ Supported Operations } & Taxi in & $\checkmark$ \\
\hline & Take-off and initial climb & $\checkmark$ \\
\hline & Taxi out & $\checkmark$ \\
\hline \multirow{2}{*}{ Storage system results } & Estored & $41 \mathrm{kWh}$ \\
\hline & Wstorage system & $243 \mathrm{~kg}$ \\
\hline
\end{tabular}

\subsection{Additional estimations: mechanical interfaces and fuel savings}

Once the main elements of the configuration have been estimated in terms of weight, before starting the comparison with the traditional architecture, it should be very interesting to perform additional evaluations in order to estimate the weight related to the mechanical interfaces of the elements and the obtainable fuel savings.

\section{Mechanical links}

As far as the mechanical connections are concerned, to perform this sizing, the technique of the "Ideal weight" proposed by prof. Gabrielli is suggested. In particular, the weight of the clutches has been estimated by evaluating the maximum friction forces and torques acting on the disks of the considered clutch.

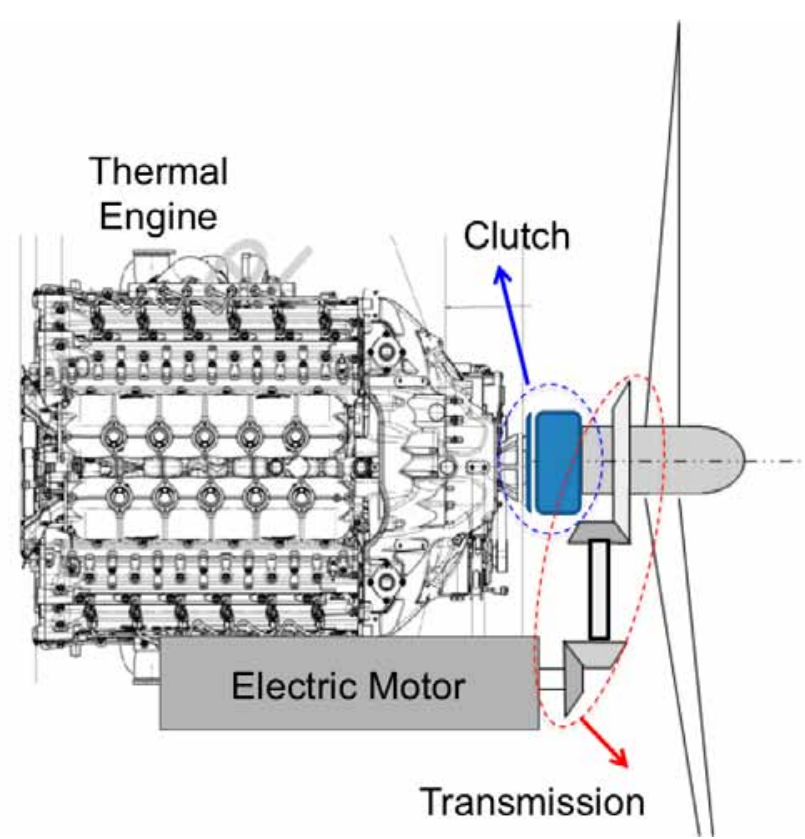

Fig. 11. Ideal mechanical connections among the different components in a parralel hybrid architecture
In particular, using the iterative process proposed in Fig. 12, the evaluation is performed assuming different values of external radius of the disk until the electric motor is able to transfer the rotation to the other element. Once the clutch has been sized, in terms of internal and external diameter, and the maximum number of disks has been selected, the weight can be estimated considering an ideal density value, depending on the constructive material.

Following the same procedure proposed in the previous section, the results for the reference case are

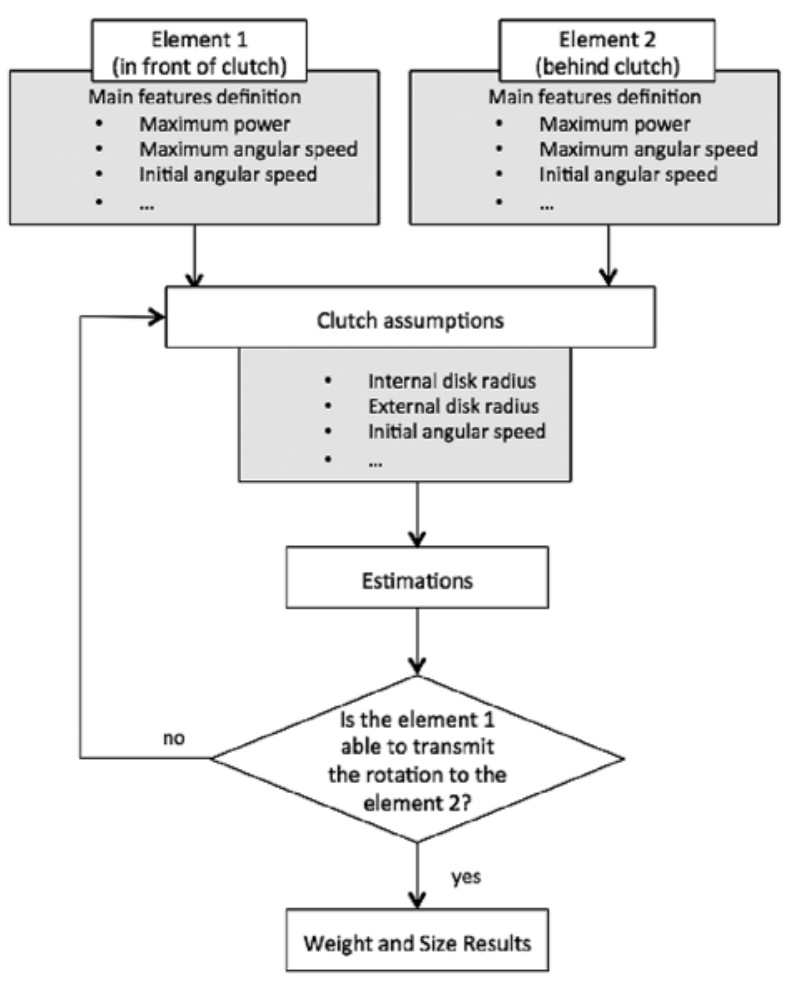

Fig. 12. "Ideal Weight" sizing methodology applied to a clutch weight estimation 
proposed. The estimations performed suggested that for a propulsion system that should guarantee a total amount of power of $195 \mathrm{~kW}$, with an hybridization degree of $40 \%$, additional $15 \mathrm{~kg}$ should be taken into account for the mechanical links.

\section{Fuel savings estimation}

As it has been said at beginning of this paper, the primary motivation for the design of a hybrid propulsion system, schematically shown in Fig. 11, is the reduction in pollutant emission. The specific computation in terms of pollutant particles introduced in the atmosphere would require sofisticated mathematical models with interesting results; however, they are not so meanigfull for the preliminary design purpose. Conversely, a strictly related estimation can be performed, taking into account the fuel consunption. Indeed, considering the power reduction of the thermal engine and its different design point, the fuel saving estimation can be performed. The results obtained for the reference configuration are provided in Table 8.

\section{Trade-off studies and parametric analysis}

The design of a new airplane is a recursive and iterative process in which there are also some decisional points. They are mandatory because, especialy in the very first phases of the project, different solutions are proposed but only some of them can be studied in-depth. In this case, the trade-off analyses are necessary to properly select the hybridization degree and the maximum capacity of the storage system.

\subsection{Safety considerations}

The presence of a higher number of additional elements devoted to the power supply, like the electric motor, can guarantee an additional safety level. This is a result achievable due to the presence of an alternative power source, in case the main one (e.g. the thermal engine) would fail. In the past, the author has developed a simple software able to simulate a failure during the most critical take-off phase and evaluate the capability of coming back to the runway and attempting a safety-landing manoeuvre. This is an extremely meaningful analysis for a single motor while in the case of multi-engine aircraft the advantage of a hybrid configuration can be detected analysing the difference in the Balance Field Length values.

Regarding the single engine aircraft, the created software (for details see (Fusaro 2013)) allows the user to select a more suitable manoeuver to be performed once the failure of the thermal engine has occured. A simple glide, a teardrop manoeuvre (Jett 1982) and a complete double $180^{\circ}$ turn (Fig. 13) can be simulated but, in order to be conservative and respectful to the ATM laws, the last manoeuver type has been selected as a case study. Imagining that the failure happens in the climb segment immediately after the take off phase, at first the aircraft should perform a $180^{\circ}$ turn and a following glide segment in order to reach the starting point of the runway. Then, exploiting the very last altitude meters, the aircraft should perform a $180^{\circ}$ turn again and try to land safely.

Moreover, the software allows the user to perform a parametric analysis by verifying the minimum altitude at which the aircraft can complete the manoeuvre. Furthermore, it permits to verify some details of the manoeuvre like the height-loss during the most demanding turn manoeuvre. Figure 14 shows the evaluation of performing a $180^{\circ}$ turn at an altitude of $500 \mathrm{~m}$ and a roll angle of 45 degrees that is considered to be the best by (Rogers 1994). As it can be noticed, in the case that the electric

Table 8. Fuel consumption comparison between traditional and hybrid propulsive system

\begin{tabular}{llllll}
\hline & Phase & $\begin{array}{l}\text { Specific fuel } \\
\text { consumption }\end{array}$ & $\begin{array}{l}\text { Power required to } \\
\text { the thermal engine }\end{array}$ & Phase duration & Fuel consuption \\
\hline \multirow{4}{*}{$\begin{array}{l}\text { Traditional } \\
\text { propulsive } \\
\text { system }\end{array}$} & Taxi out & $0.2433 \mathrm{~kg} / \mathrm{kW} / \mathrm{h}$ & $23 \mathrm{~kW}$ & $0.0833 \mathrm{~h}$ & $0.47 \mathrm{~kg}$ \\
\cline { 2 - 6 } & Take-off and initial climb & $0.2859 \mathrm{~kg} / \mathrm{kW} / \mathrm{h}$ & $195 \mathrm{~kW}$ & $0.01667 \mathrm{~h}$ & $0.93 \mathrm{~kg}$ \\
\cline { 2 - 6 } & Cruise & $0.2737 \mathrm{~kg} / \mathrm{kW} / \mathrm{h}$ & $115 \mathrm{~kW}$ & $1 \mathrm{~h}$ & $31.47 \mathrm{~kg}$ \\
\cline { 2 - 6 } & Landing & $0.2433 \mathrm{~kg} / \mathrm{kW} / \mathrm{h}$ & $50 \mathrm{~kW}$ & $0.01667 \mathrm{~h}$ & $0.20 \mathrm{~kg}$ \\
\hline & Taxi in & $0.2433 \mathrm{~kg} / \mathrm{kW} / \mathrm{h}$ & $23 \mathrm{~kW}$ & $0.0833 \mathrm{~h}$ & $0.47 \mathrm{~kg}$ \\
\hline \multirow{3}{*}{$\begin{array}{l}\text { Hybrid } \\
\text { propulsive } \\
\text { system }\end{array}$} & Taxi out & - & & TOTAL & $33.54 \mathrm{~kg}$ \\
\hline & Take-off and initial climb & $0.2433 \mathrm{~kg} / \mathrm{kW} / \mathrm{h}$ & $115 \mathrm{~kW}$ & $0.01667 \mathrm{~h}$ & $0.46 \mathrm{~kg}$ \\
\hline & Cruise & $0.2433 \mathrm{~kg} / \mathrm{kW} / \mathrm{h}$ & $115 \mathrm{~kW}$ & $1 \mathrm{~h}$ & $27.97 \mathrm{~kg}$ \\
\hline
\end{tabular}


motor of a hybrid configuration is able to guarantee at least $66.5 \mathrm{~kW}$, the aircraft would be able to perform a sustained turn mantaining the same altitude. These evaluations have been carried out for the entire landing path by exploiting the variations connected to the height at which the failure occurs, the roll angle and the radius of the turn; however, the most interesting one is the one reported in Fig. 15. It is the Minimum safety failure altitude as a function of the residual power.

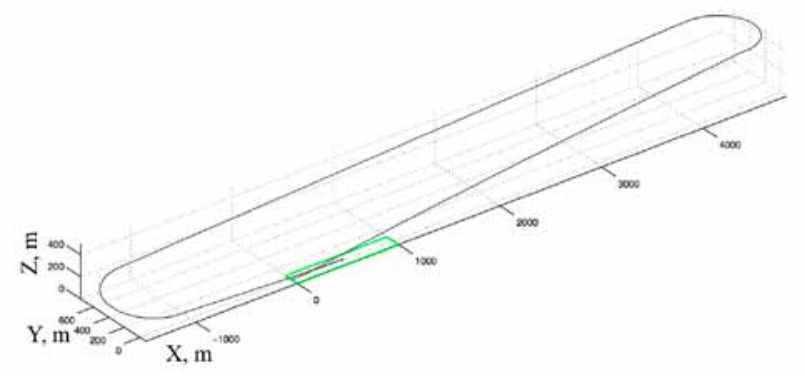

Fig. 13. Double $180^{\circ}$ turn manouver

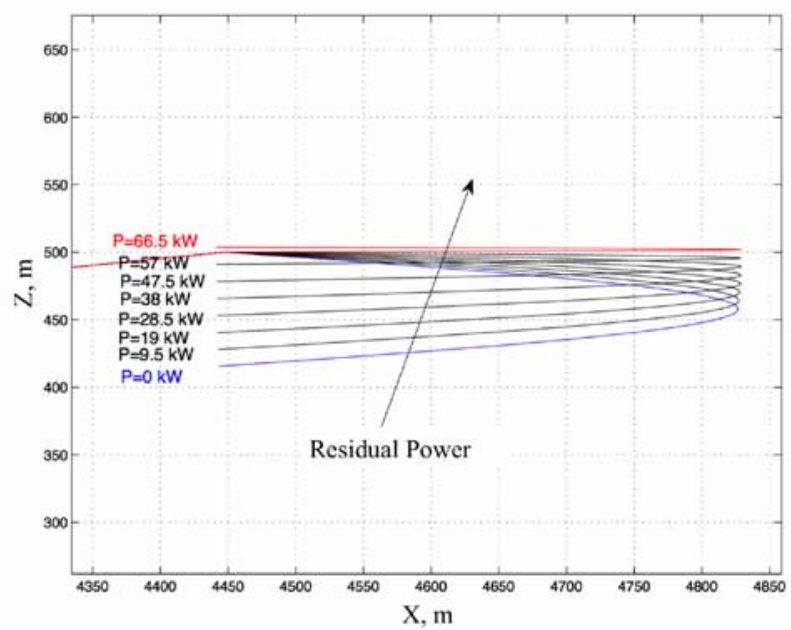

Fig. 14. Lateral view of different turns, at different residual power levels

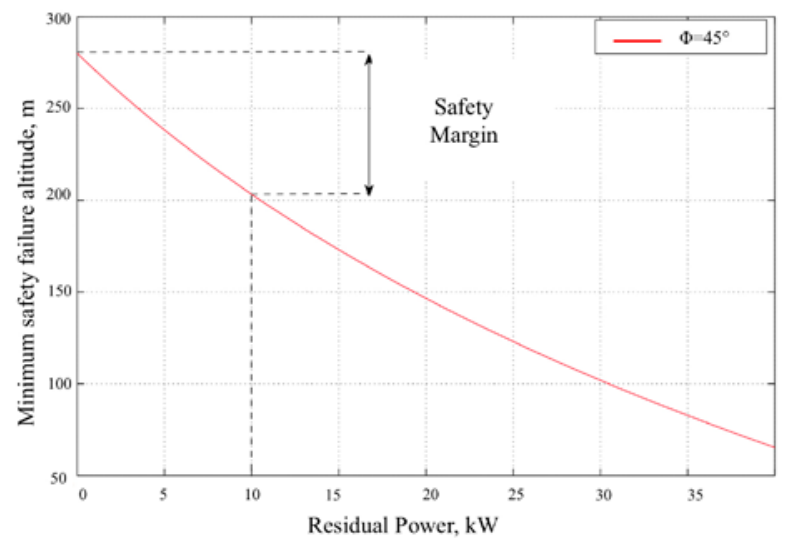

Fig. 15. Minimum safety height as a function of residual power
This curve shows that if the aircraft has a certain amount of residual power after the thermal engine failure, the pilot can land safety even if the failure happened nearer to the ground. More specifically, for the aircraft selected as the reference, a $10 \mathrm{~kW}$ electric motor is sufficient in order to allow a safety manoeuvre in the case of thermal engine failure at an altitude higher than 200 $\mathrm{m}$. This basic safety estimation can be useful in order to set an additional requirement in terms of safety. For example, the customer can request a minimum safety margin of $100 \mathrm{~m}$. In this specific case, in accordance to Fig. 15 , an electric motor of $30 \mathrm{~kW}$ can be sufficient to comply with the safety requirement.

\subsection{Weight variantions as a function of the hybridization degree.}

The previous weight estimations have been performed considering the hybridization degree selected in Section 3.2 , but the aircraft design is an iterative and recursive process during which some variations should be taken into account. In particular, the author thought that it could be very useful to implement the previously described methodology within a simple software in order to verify and evaluate the impact of changes in the overall propulsive system weight much easier.

For example, if the reader only considers the electric motor and the thermal engine, it is possible to verify that a higher hybridisation degree selection would imply a very interesting reduction in weight. Unfortunately, the state-of-the-art batteries turn this advantage into a significant drawback.

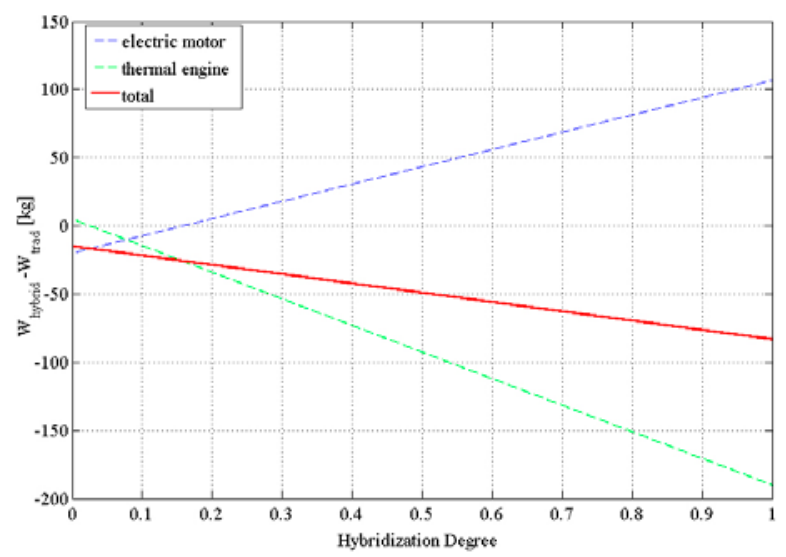

Fig. 16. Thermal engine and electric motor trends as functions of the hybridisation degree

\section{Conclusions}

The aim of this paper is to evaluate and summarize the possible benefits of a hybrid propulsion system applied to a single engine piston prop aircraft. In order to perform this task, a proper methodology for the preliminary design of a hybrid airplane has been proposed and 
applied to a reference case study. This process highlighted that the main drawback, in terms of additional weight, is directly connected to the storage system, but it allows the reader to discover other numerous benefits. In particular, the reduction in fuel consumption and the safety margin exploitable during the take off phase will be the most interesting for future customers. Furthermore, this hybrid solution will guarantee a noticeable decrease of pollutant emission in the atmosphere and the reduction of the aircraft footprint in airport area due to the Green Taxi feature.

In the the following years, with the development of an innovative high-density storage system, hybrid propulsive systems for small aircraft could represent a new and attractive portion of the market, especially in the General Aviation Field.

\section{Contribution}

The Author, PhD Student in the Mechanical and Aerospace Department of Politecnico di Torino, would like to thank Prof. Sergio Chiesa and Dr Marco Fioriti for their contribution to this research.

\section{Disclosure statements}

The Authors declare to have no competing financial, professional or personal interests from other parties.

\section{References}

Adnanes, A K. 2003. Maritime electrical installations and diesel electric propulsion. 1st ed. Oslo: ABB AS Marine.

Chiesa, S.; Fioriti, M.; Viola, N. 2012. Methodology for an integrated definition of a System and its Subsystems: the case-study of an Airplane and its Subsystems, in B. Cogan (Ed.). Systems engineering - practice and theory, INTECH [online]. Available from Internet: http://cdn.intechopen. com/pdfs/32615.pdf

Fioriti, M. 2014. Adaptable conceptual aircraft design model, Advances in Aircraft and Spacecraft Science 1: 43-67. http:// dx.doi.org/10.12989/aas.2014.1.1.043 ISSN 2287-528X

Fusaro, R. 2013. Hybrid Propulsion in Aeronautics, Master Thesis. Politecnico di Torino. Torino.

GAMA. 2010. General Aviation: Statistical Databook \& Industry Outlook [online]. Available from Internet: http:// www.gama.aero/files/GAMA_2014_Databook_LRes\%20 -\%20LowRes.pdf

Gosh, R.; Schilling, T.; Wicke, K. 2014. Theoretical framework of the system design for the air transportation system including an inherently quantitative philosophy of scenario development, in $29^{\text {th }}$ ICAS Congress, 7-12 September 2014, Saint Petersburg, Russia.

Husain, I. 2010. Electric and hybrid vehicles. Design fundamentals. 2nd. Ed. Boca Raton, London, New York: CRC Press.

INCOSE. 2014. System Engineering Handbook. Wiley.

Jett, B. W. 1982. The feasibility of turnback from a low altitude engine failure during the take off climb out phase, in AIAA $20^{\text {th }}$ Aerospace Sciences Meeting $50^{\text {th }}$ Anniversary Celebration, 11-14 January 1982, Orlando, USA.

Lausetti, A. 1992. Decollo e Atterramento. Torino: Libreria Editrice Universitaria LEVROTTO \& BELLA.
Leggett, J. A.; Elias, B.; Shedd, D. T. 2012. Aviation and the European Union's Emission Trading Scheme, 7-5700 R42392, Congressional Research Service.

McCoy, T. J. 2002. Trends in ship electric propulsion, in Power Engineering Society Summer Meeting, IEEE 1. ISBN: 0-7803-7518-1

NASA. 2014. System Engineering Handbook. Washington DC: NASA.

Public Law. 2012. European Union Emissions Trading Scheme Prohibition Act of 2011, in 112th Congress of Public Law, 27 November 2012. 112-200 p.

Rogers, D. F. 1994. The possible "impossible" turn, in AIAA Journal of Aircraft 32: 392-397. http://dx.doi. org/10.2514/3.46728

Siemens, Diamond Aircraft and EADS. 2011. World's first serial hybrid electric aircraft to fly at Le Bourget, Press Release, 20 June 2011. 